\title{
WHEN COMPANIES Don'T MAKE THE Ad: A MUlTI-METHOD INQUIRY INTO THE DIFFERENTIAL EFFECTIVENESS OF CONSUMER-GENERATED ADVERTISING
}

\author{
Benjamin Lawrence \\ (Ph.D. Boston University) \\ Assistant Professor \\ Cornell University \\ School of Hotel Administration \\ 246 Statler Hall \\ Ithaca, NY 14853 \\ 978-254-1669 (phone) \\ 617.255.4179 (fax) \\ benlawrence@cornell.edu \\ Susan Fournier \\ (Ph.D. University of Florida) \\ Professor \\ Boston University \\ School of Management \\ 595 Commonwealth Ave \\ Boston, MA 02215 \\ 617.353.2773 (phone) \\ 617.353.4098 (fax) \\ fournism@bu.edu \\ Frédéric Brunel \\ (Ph.D. University of Washington) \\ Associate Professor \\ Boston University \\ School of Management \\ 595 Commonwealth Ave \\ Boston, MA 02215 \\ 617.353.4609 (phone) \\ 617.353.4098 (fax) \\ brunel@bu.edu
}

February 7, 2013

Forthcoming Journal of Advertising

All correspondence should be addressed to Benjamin Lawrence (benlawrence@cornell.edu) 


\title{
WHEN COMPANIES Don'T MAKE THE Ad: A MUlTI-METHOD INQUIRY INTO THE DIFFERENTIAL EFFECTIVENESS OF CONSUMER-GENERATED ADVERTISING
}

\begin{abstract}
This four-part multi-method investigation into the under-researched yet increasingly prevalent phenomenon of consumer-generated advertising (CGA) confirms a performance advantage over traditional advertising and suggests a rationale for this differential. CGAs benefit from heightened consumer engagement and increased trustworthiness. CGAs also garner perceived quality advantages that are linked to consumers lowering their expectations and using different evaluation criteria to judge the ad. The ad creator — a personalized, identifiable and relatable entity in the case of CGAs - plays a central role in anchoring and shaping ad reactions. The “consumer-made” characteristic — the fact that CGAs are not made by companies but by independent people_-is powerful and stands strong in the face of commercial motives, and presents paradigmatic implications for advertising practice and research.
\end{abstract}


One of the marketing consequences of recent technological innovation is consumergenerated advertising (CGA): consumer-created brand communications with the look, feel, form and intent of traditional advertising (Ertimur and Gilly 2011). Though marketers have, for decades, solicited consumer feedback in the process of creating ads (e.g., communication ideas, slogan contests, testimonials), the CGA phenomenon is unique in that access to multimedia software, the internet, and social media platforms now allow consumers to create, produce and disseminate ads. Marketers have increasingly used or co-opted CGAs as campaign elements since the practice was first noted (Ives 2004). For example, in 2007, Frito-Lay, General Motors, and the NFL placed solicited CGAs in the Super Bowl, the most expensive and broadestreaching marketing medium available (Lippert 2010). While Frito-Lay returned to the Super Bowl for the sixth time with a CGA campaign in 2012, a broad range of companies committed to mainstream brand-building have now added CGA to their communications mix: Nike, Unilever, Heinz, Microsoft, Google, General Mills, NBC, Converse, Mini Cooper, Folgers, Yum Brands, Amazon, and Procter \& Gamble, to name a few. By these accounts, the practice of leveraging consumer-created brand messaging has come of age.

Supporters frame CGA as a game-changing solution to pressing marketing problems: CGAs cut through the clutter with resonant and authentic messaging at lower costs (Creamer 2007; Mills 2006). Performance results have been encouraging. CGAs for the flagship Doritos brand won awards for the sixth time in 2012 (fritolay.com). According to Ann Mukherjee, Group VP Marketing, Doritos’ CGA campaigns have been the most successful marketing initiatives in the brand's history, garnering improved performance on metrics including pass-along value, online currency, media value, and brand equity (Burstein 2012). Over the past four years, CGAs have consistently drawn the most positive ratings in the Super Bowl Ad Review 
(http://www.kellogg.northwestern.edu/news/superbowl), ranked in the number one spot in USA Today's Ad Meter rankings (Petrecca 2012), generated the most Tweets and positive sentiments in the Mullen Brand Bowl (brandbowl2012.com), and supported the "most buzzed about brands" according to Nielsen BuzzMetrics (Elliott 2010). The success of CGAs in media environments where they are consistently the most watched, the most memorable, and the most-often-talkedabout ads hints at the potential psycho-social advantages of this communications form. CGAs have emerged as a valuable component in the marketing communications arsenal in light of a popular belief that they perform strongly versus traditional ads.

An equally-persuasive case against CGAs can also be leveraged (Deighton and Kornfeld 2009). High profile mishaps including the so-called failed Chevy Tahoe experiment (Neisser 2006) and numerous parody-heavy CGA campaigns such as those for Dove and United Airlines (Deighton 2008; Deighton and Kornfeld 2010) cause many to debate the wisdom of consumercreated messages that open the brand to disaster (Neisser 2006) and subversive attacks (Berthon, Pitt, and Campbell 2008). Critics argue that as the practice matures, the creator's status as a nonprofessional, everyday consumer becomes clouded by motives for professional advancement or profit, weakening CGA authenticity in kind (Ertimur and Gilly 2011; Moscowitz 2006). Increased company involvement in CGA sourcing further strains its credibility advantages (Thomaselli 2010). Ironically, the ubiquitous technologies that have supported the rise of CGAs also threaten the phenomenon by enabling an ever-increasing number of potentially undistinguished, forgettable and bad ads (Moscowitz 2006; Thomaselli 2010).

Although marketers might be anxious to put consumers to work creating ads, the reality of mixed anecdotes and scant empirical evidence make this a risky stance. We know who is making CGAs, why they are making them, and what types of CGAs they are making (Berthon, 
Pitt, and Campbell 2008; Daugherty, Eastin, and Bright 2008; van Dijck 2009; Ertimur and Gilly 2011), but very little is known about the effectiveness of CGAs or the drivers of such effects. Although advertising rankings such as the USA Today's Ad Meter support the contention that CGAs are more effective than traditional company ads, empirical evidence is inconclusive. Some suggest increased performance because of enhanced trustworthiness (Muniz and Schau 2007) and authenticity (Ertimur and Gilly 2011). Steyn and colleagues (Steyn, Wallström, and Pitt 2010; Steyn et al. 2011) find no differences in ad likability or viewer response profiles (i.e., empathy, familiarity, entertainment, confusion, relevant news, brand reinforcement, alienation) for CGAs versus company ads. Others suggest that CGAs are actually less credible and are evaluated more critically (Ertimur and Gilly 2011; Thompson and Malaviya 2011). The exclusive use of qualitative methodologies and/or study designs that restrict the range of criterion and process variables explain some of these conflicting results. In this research, we leverage an exploratory qualitative analysis, two experiments, and a follow-up survey to develop a comprehensive inquiry that addresses two fundamental yet unsettled questions regarding this popular advertising phenomenon: do CGAs have communications advantages over traditional company-sourced ads and why?

\section{RESEARCH OVERVIEW}

We designed a multi-method, multi-study research program to investigate whether and how CGAs might work to persuade. Consistent with an adapted etic approach (Micu, Coulter, and Price 2009), we first leverage qualitative data to better understand the CGA phenomenon and generate hypotheses for testing. In line with published research involving consumer-created content, we utilize YouTube as a data source (Campbell et al. 2011; Keelan et al. 2007). We follow the purposive logic of qualitative research that focuses on archetypal or extreme stimuli 
for the privileged insights these allow (Patton 2001) and analyze posted comments for eight successful and high-profile CGAs. We uncover four themes that may drive enhanced CGA effectiveness: trustworthiness, identification with the ad creator, judgments of executional quality, and viewer engagement. Based on these themes, relevant literatures are leveraged to develop five hypotheses concerning differential CGA effects.

In the spirit of Olson and Thjømøe (2011), two experiments and a survey follow our exploratory study and test the inducted hypotheses. The first experiment informs the roles of source factors and engagement in driving CGA responses while also offering evidence of the overall effectiveness of CGAs versus company ads. A second experiment manipulates ad quality to investigate its role in driving CGA effectiveness and replicates tests of a CGA performance differential. A follow-up survey probes the role of evaluation standards and judgment criteria as mechanisms behind perceived quality effects.

Across a set of accepted measures of ad persuasion, these studies establish that there is a performance advantage for CGAs and suggests a rationale for this differential. We find that it is the fact that CGAs are made by people, not companies, that drives responses to this class of ads.

\section{STUDY 1: IDENTIFICATION OF FACTORS DRIVING CGA RESPONSE}

The purpose of the qualitative exploration was to identify themes implicated in the viewing experience for successful CGAs so as to formulate hypotheses regarding factors driving their potential effectiveness. We studied one month of YouTube conversations concerning eight CGAs noted in the press as successful campaigns. The ads span product categories (cars, personal care, snack food), involvement levels (high versus low), and advertising strategies (informational, humor, and image). The ads were all contest-generated CGAs that aired in high- 
visibility television environments. The ads were clearly identified in the postings as contestgenerated and consumer-created; creator bios or storylines were linked to each ad.

Five ads were included from perhaps the most well-known of CGA campaigns: a competition for Unilever's Dove Cream Oil, the winner of which was aired during the 2008 Academy Awards (Deighton 2008). We analyzed the winning ad in the competition (Knowing You're Beautiful with 217 posts), two finalists (Fly Like a Dove and Live in Color with 53 and 57 posts, respectively), the most popular submission per YouTube viewer ratings (Feeling Divine, 51 posts), and the submission downloaded most often (Wash Away the Lines, 63 posts). Viewer comments for three additional competition-generated CGAs that aired during the 2008 Super Bowl were analyzed: two winning ads from the "Doritos: Crash the Superbowl" competition (Live the Flavor and Check Out Girl, with 92 and 140 posts) and the award-winning ad from the “Chevy Superbowl College Ad Challenge” for the Chevy HHR brand (Carwash, 56 posts).

Our dataset included 729 unique postings across the eight ads. Thematic coding was conducted independently by four judges and discussed jointly among team members; four major themes were uncovered. Below, we share data illuminating each theme. After each exposition, we review relevant selected literature to support hypotheses claiming differential advantages for CGAs versus traditional company ads.

\section{The Role of Trustworthiness in CGA Reception}

Comments support that CGAs are distinguished in part by the people who serve as their creators, and commentary indicates the operation of the inherent trustworthiness of ads from this source. Of particular note is the perceived authenticity of both the creator and his/her ads. Postings indicate an appreciation of "real people," "not companies,” making "real, honest ads."

This commercial was made by REAL people reaching out to OTHER real people about very common concerns. it can catch the attention of all consumers.- Dove 
I loved your video. I don't know if you've had lessons or not. (I bet you haven't, you seem like a natural.) I hope your video wins. - Dove

Authentic CGAs were considered more credible, "honest," and "wholesome” than ads from a "slick multinational industry" that "manipulates consumers” and "shills brands.”

The honesty truly shows and sells in this commercial...honesty sells in an overwhelmingly superficial society. - Dove

Thank you for the honest, direct idea. I love it and so will the rest of America. - Dove

I liked this ad because it didn't go for the false sincerity and phony, glam-crazed, Hollywood "image of perfection" attitude.-- Dove

Extensive social psychological research supports a central role for trustworthiness in driving persuasion and communication effectiveness (Wilson and Sherrell 1993; Hovland and Weiss 1951), and a strong argument can be made for expected CGA advantages versus traditional ads on this front. Messages created by trustworthy sources encourage source and message bolstering (Yalch and Elmore-Yalch 1984) while material created by less trusted sources induces counter argument and source derogation (Wiener, LaForge, and Goolsby 1990). Bickart and Shindler (2001) invoke source credibility to explain why consumer-generated communications are more effective than company-sourced information in engendering interest. Such messages are independent from the marketer and are perceived as having been created by individuals with no vested self-interest, ulterior motives or intentions to manipulate (Beverland and Farrelly 2010; Verlegh et al. 2004). Information posted by consumers on discussion boards follows this logic and engenders more trust than manufacturer-provided information (Cheong and Morrison 2008). Building from our findings and this literature, we therefore propose:

$\mathbf{H}_{1 \mathbf{a}}$ : CGAs and their creators are viewed as more trustworthy than company ads. 
The data also reveal that CGAs whose creators fail tests of credibility or authenticity are lamented and openly criticized. Many counterarguments were registered concerning ads produced by "professionals" with "industry training" and "an obvious leg up in the equipment and skills needed for high quality production.” Wariness concerning people who contribute ads “just to get clients” was expressed. Comments reflect general disdain regarding professional or company involvement in a "contest that was supposed to be about the people, pure."

Corporate stuff, produced by proffesionals for a supposed contest... Cute, but come on, have a real contest! - Doritos

I checked this out, this spot was produced and entered by professional film makers that worked on Hollywood films like Terminator, etc... check out their website. for a supposed Consumer Generated Content Contest? corporation generated..more like it? What's up with this, should be called PRO-sumer Generated Video - Doritos

A friend of mine who lives in CA sent me a link to GoddessLams Myspace page and she owns a production co...this is WHY this is such a great video...much easier to do with high quality cameras and editing equipment...totally against the rules!!! - Dove

Indeed, though creators' motivations play a vital role in establishing credibility, authenticity and trustworthiness (Eagly, Wood, and Chaiken 1978), not all CGAs are equal on this front (Daugherty, Eastin, and Bright 2008). Some CGAs are created by consumers motivated by love of the brand or enjoyment of the craft while others are created for purposes of selfpromotion and the desire to profit economically or professionally (Berthon, Pitt, and Campbell 2008). Competition-inspired CGAs can exacerbate this issue by violating the assumption that CGAs are distanced from corporate contamination and adding semi-professionals into the creator mix. For these reasons CGAs motivated by self-gain are generally viewed as less authentic and more contrived (Thomaselli 2010). Supporting this, Ertimur and Gilly (2011) found that competition CGAs are viewed as less authentic than their organic counterparts. Our qualitative 
data supports that perceptions of economic motives damage the perceived trustworthiness of the ad and its creator. Thus, we propose the following qualifying effect:

$\mathbf{H}_{\mathbf{1 b}}$ : CGAs whose creation is driven by economic motives are less trusted than those whose creation is driven by non-economic motives.

\section{Source Identification as a Driver of CGA Reception}

The data suggest that having consumers in the role of ad creator also provides a basis for personal connections that can contribute to favorable CGA reception. Some viewers compared themselves to the ad creators or made connections with them along different lines.

I have always wanted to learn how to skydive and this is so inspiring. This woman is a bit older like me. I guess it is never too late to start - Dove

Im so glad this can happen to you A regular person like me Just goes to show dreams are possible Now my dream of possibly starring in a commercial is just that much more imaginable - Dove

Social influence research supports that people are more likely to be persuaded by those who are judged to be more similar to them in values or other characteristics (Hilmert, Kulik, and Christenfeld 2006; Wilson and Sherrell 1993). For example, Brock (1965) and Busch and Wilson (1976) found that salespeople sold more products when customers perceived the salesperson as having similar qualities and interests. Perceived similarity engenders a greater level of interpersonal attraction, understanding, and trust (McPherson, Smith-Lovin, and Cook 2001). CGA is unique in that the source of the ad is typically identified, as, for example, through tags on YouTube to creator biographies or in marketing publicity showcasing the people submitting CGAs (Horovitz 2009; Petrecca 2012). When CGAs are developed by so-called everyday people, this allows source comparisons that ad agencies cannot obtain. Pilot research in the CGA space suggests that higher levels of consumer-creator similarity can lead to higher ratings for the CGA (Thompson and Malaviya 2011). We propose that CGAs are inherently more able to 
generate source identification because of the face they put on the ad creator versus the anonymity

of the source of a traditional company ad. Accordingly:

$\mathbf{H}_{2}$ : Consumers personally identify with CGA creators more than they do with the companies or agencies that create ads.

\section{Engagement with CGAs as a Driver of Response}

The YouTube data also supports that successful CGAs deeply engage viewers and that engagement may drive ad response. Four different forms of engagement were manifest: cognitive, emotional, personal and behavioral. Postings concerning cognitive engagement involved the thoughtful processing of the ad and its message claims. Some comments provided simple playback of messages or executional elements ("Ah yes 'The shower is our sanctuary."; "The poetry...Every woman in the world should know these words by heart!") or mentioned characters and elements in the ad ("I love how the actress smiled at the end!"; "The woman in the ad is enjoying the product, feeling beautiful and there is a cute expression on her face when she kind-of 'realizes' someone might be 'watching'...”). Deeper cognitive engagement included counter- and support-arguments as well as reflections on the take-away of the ad. Unique characteristics of CGA offered additional avenues for elaboration, and included thoughts about the CGA contest venue, the ad creators, and specifics about the ad production process itself.

She chose various aspects to appreciate in women everyday. 1 . The bravery all women have to survive daily - even if not to the extreme of jumping from a plane. The need NOT to judge based on "black and white" decisions but realize the deeper complexity of issues, to "live in color." 3. The power of imagination to set us free or transform moments of fantasy into reality. - Dove

If the winner had been chosen by \# of hits, looks like it would have been "Wash Away the Lines"...3 days ago they had 13,000,000...now they've got over $100,000,000 .$. guess had it been "American Idol" style of voting and it's all the public, then they would have been \#1!! - Dove 
It is us that makes the product. We should always be aware of our strength as women. The commerical is not to teach us what we already know about ourselves but to remind us that we are the most important part. - Dove

Emotional engagement in the form of sensory and experiential pleasure from or immersion in the ad viewing experience was also manifest. This form of engagement derived largely from the pure entertainment value offered in viewing the ad.

Great Commercial!! Every year we anticipate the super bowl commercials and this year the one that had us all cracking up was the Chevy car wash commercial.. I think it was hilarious, the old gentleman really had me in stitches. The room went wild when this one came on." - Chevy HHR

ABSOLUTELY AWESOME! Where did you find that CHECK OUT GIRL? She's hilarious!! LOL! I still can't stop laughing! Funniest commercial yet! - Doritos

Also evident was a personal form of engagement in which the relevance of the brand or ad message to the person's life was expressed. Comments revealed a person's connection with the brand or past brand experiences. Personal engagement often manifest in the sharing of brand stories and other illustrations of links between the brand and self. Both positive and negative personal connections were shared.

I loved this one and so did my sister, she called long distance just to say she was ready to buy a Chevy and we talked about how our dad and his dad used to own a chevy way back when. - Chevy HRR

As a mother of two very strong and secure adult daughters, I am proud that they do not need marks on their bodies or watch unrealistic plastic surgery shows. No one should want EVERYTHING changed. - Dove

My family has been associated with the sales of Chevrolet vehicles since 1928....Grandfather....father and me.... SUPER BAD AD...customers have even called my cell phone wanting to contact GM to state their dislike...disgust - Chevy HHR

Lastly, we identified behavioral engagement as reflected in actions involving three focal objects: the brand, the ad creator, and the ad. Classic examples of brand-centric behavioral engagement included purchase behaviors and recommendations to others (e.g., "I'll buy a 
chevy!"; "We want the products that we use everyday to help our skin stay beautiful. DOVE is that product!"; "WAY TO GO CHEVY! make us excited about an AMERCIAN product!...BUY WHAT AMERICANS BUILD...BUY CHEVROLET!!!). Brand-related behavioral engagement in the form of helping behaviors was also noted, as with posters who shared or requested useful information (e.g., "You should write to them and tell them your thoughts. The company website is here..."; "I did an experiment with some friends last year. I told 5 of them to eat a bowl of Doritos equivelent to about 2 snack bags about a half hour before bedtime. 4 out of the 5 had terrible nightmares. Try it yourself and see what happens. I promise it will help you cut down on junk food.). The YouTube environment also effectively encouraged brand-related debates among viewers, as in the below discussion about the true meaning of the Dove brand.

This ad is sending the wrong message......... why would you advertise on a Dove commercial that you should change everything about yourself? NO, this commercial asks "If you could change something, what would you change?"..the girl who later responds "everything" demonstrates how distorted our views of ourselves are. The ad ACTUALLY says women DON'T need to constantly think about their "flaws"; "wash them away."

I agree with her. Beauty comes in all forms and this commercial encourages all women to be proud of their beauty.- Dove

Behavioral engagement in the form of direct conversations with and probes of CGA creators was evidenced as well. Creator dialogue was engaged for specific informational purposes (e.g., "how did you do that?”, “do you have training in this?”, "how do you feel about the way the winner was decided?") or simply to register recognition, admiration and support ("Hats off to you Freshman gal ad creator!"; "I think this is the winner-- don't pay any attention to all the propoganda below. You are a cool woman and this is a super-cool video! Congradulations because you totally deserve it”). Viewer-creator dialogue was sometimes intimate and on a first-name basis, and reflective of relationship-building goals ("Patty, thanks for making this! I look forward to hearing and seeing more from you! can you send me more of 
your ads?”). Outreach toward creators sometimes included self-disclosures as signals of relationship deepening and, in select cases, relationships were pursued offline ("Hey PRETTYGEMS...I have something to tell you and don't want to post it here...write me at:azashley60@aol.com”). Alliances and sub-groups sometimes formed as people took sides with creators along issue lines:

ashmannley. stop being so judgmental. you don't KNOW the other two contestants. take a look at other videos. so kiss it. because you're wrong. she's right ashmannley. Quit it. - Dove

Ad-relevant behavioral engagement was also evident, as indicated in comments about (re)viewing, forwarding or registering support for the ad: "I just keep coming back to this one; so well-done and clear"; "I think that I have viewed this clip at least 4 x s";" had to watch it several times to catch it all"; "we all loved it on the superbowl so the next day I went to YouTube to find it so I could watch it again. You can check it out also on dovecreamoil.com"; "I looked at this ad at the beginning of the contest and came back to it again after seeing it on Access Hollywood and show friends and family how much I LOVE it..."; "Thank you for the ad. I sent this to my daughters. they really need to hear what you say"; "you can vote as many times as you like so I am going to do that.”; “This one is good , but check out the other Top 10...”).

Although arguably not a new concept or term, recent changes in media and marketplace dynamics, and, in particular, the increased prominence of the notion of co-creation, have brought engagement to the forefront amongst advertising concerns. In 2006, the Advertising Research Foundation, the Association for National Advertisers, the American Association of Advertising Agencies, the Direct Marketing Association, and the Interactive Advertising Bureau formed a task force to better define and build knowledge around this phenomenon (Plummer 2006; Plummer 2007). This initiative generated much debate and writing, especially in the professional 
press and in the form of industry whitepapers (e.g., Evans 2012; Haven 2007). Academics across varied disciplines including marketing as well as psychology, organizational behavior, computer sciences, sociology, political science, and education have joined this growing conversation (for an exhaustive review along with research propositions and implications, see Brodie et al. 2011). Engagement has emerged as a central construct in services research (see the recent 2011 special issue of Journal of Service Research). In the advertising realm, engagement has been empirically linked to more positive advertising responses and higher levels of persuasion (Calder, Malthouse, and Schaedel 2009).

The ARF and the 2006 taskforce define engagement as "turning on a prospect to a brand idea enhanced by the surrounding context.” Albeit useful, this definition lacks specifics regarding the nature and experience of engagement, or the facets that comprise the response. Toward the goal of increased conceptual rigor, Mollen and Wilson (2009) offer a three-part model that includes cognitive engagement (a mental state accompanied by active and sustained cognitive processing and elaboration), personal engagement (the satisfaction of utility and personal relevance) and emotional engagement (the sensory-emotive experience that can characterize interactions). As evident in our qualitative data, engagement also includes an additional facet of behavioral interactions (see also Calder, Malthouse, and Schaedel 2009; Hollebeek 2011) reflecting the inherent interactivity of co-creative processes. This may include the co-creation of content (Hoyer et al. 2010; Kumar et al. 2010) and a variety of brand- or adfocused social behaviors including word-of-mouth activity, consumer conversations, posting and sharing of links, blogging, recommendations, and writing reviews (MarketingNPV Journal 2008; Van Doorn et al. 2010; Verhoef, Reinartz, and Krafft 2010). In their integrative review, Brodie et al. (2011) incorporate behavioral engagement as one of the key dimensions of engagement. 
Although engagement shares aspects with the involvement (Krugman 1965), including personal relevance (Zaichkowsky 1985) and interest or cognition (Park, Jaworski, and Maclnnis 1986), current conceptualizations see it as significantly different in that engagement is a contextspecific concept that implicates interactive, co-creative, psycho-social experiences involving a focal object such as an ad, brand, website, or store (Brodie et al. 2011). Involvement (along with flow) is thus a required but not sufficient antecedent of engagement response (Brodie et al 2011). Because CGAs, as participatory communications (Kalehoff 2006), are inherently based on consumers assuming the role of creator and/or being more centrally involved as contributors to meaning making and message diffusion, the co-creative and interactive experiences linked to CGAs serve as a basis for greater engagement (Brodie et al. 2011). As a context and/or focal object, CGA provides opportunities for the activation of mental associations and experiences that lead to the co-creation and personalization of brand meaning and co-ownership of the brand and thus greater engagement (Plummer 2006). The brand debates in our YouTube data showcase some of these processes of negotiated meaning making that might not manifest in companycontrolled ads. We also find evidence concerning engagement sparked by CGA creators—a personalized and relatable entity that plays a pivotal role in consumer experiences with CGAs. Postings suggest that CGA creators may operate as catalysts for deeper engagement by providing not-available-in-traditional-advertising contact points and personal connections into the community. CGAs also put a face on otherwise nameless ad creators, and this personalization can spark personal comparisons, underdog associations (Paharia et al. 2011), or effectively invoke drama to persuade (Deighton, Romer, and McQueen 1989). CGA competitions themselves bring additional avenues for engagement, as when consumers discuss contest efficacy and rules. Because CGAs provide greater opportunities for elaboration, reflection, and, in 
general, co-creation and ownership of meaning, we propose CGAs should engage people more (across all facets of engagement) than traditional company ads.

$\mathbf{H}_{3}$ : CGAs are more engaging than company ads.

\section{Perceived Ad Quality and the Reception of CGAs}

Perceptions about executional quality played a role in viewer reactions to CGAs, as they do for traditional advertising. Quality-related comments were almost exclusively positive for the posted CGAs (e.g., "Very well done! Amazing!”; “ Looks like a commercial done by the professionals!”; “OUTSTANDING! Awesome job with this ad”). Comments indicated reflection on executional factors contributing to ad quality judgments: music, lighting, production value, acting, etc. Evaluations of CGAs were also derived from ad attributes beyond executional quality, and included consideration of authenticity and creativity credentials. Comments lauded CGAs as "original” and "artistic” and not "basic," or "stereotypical” like "other ads.”

Background colors are perfect: An A+. So thoughtful, so creative, so well done. - Dove Very engaging compelling ad. Great acting. Nice job with the original music, too! - Dove I like this ad. The creativity just flows. - Dove out of all 5 this one is my \#1, it is the most original - Doritos

Many who commented also stressed the superior quality of these "amateur ads" and indicated that they had exceeded their expectations.

This one's awesome! Especially the fact that it was created and written by a freshman girl in college! Hats off to her! - Chevy HHR

I did not expect something this good from young college students - Chevy $\mathbf{H H R}$ It's amazing ... a teenager made this???? - Dove 
The data also suggest that some viewers had different standards for judging consumergenerated ads: standards that were not as stringent on quality or that accepted trade-offs in light of the added authenticity of something consumer-made.

This video doesn't look professional. It looks really good for an amature, though! - Dove Why all the criticism about the ad? This ad should be celebrated for its originality, creativity and clear message not condemned for its flaws. - Dove

Collectively, the data on quality perceptions suggest that CGAs might be perceived more favorably because of disconfirmed expectations for poor quality and differential weighting of other advertising attributes such as authenticity and creativity. Executional quality stands as a key determinant of attitudes towards the ad: ads high in executional quality outperform those low in executional quality and drive positive attitudes toward the brand (MacKenzie, Lutz, and Belch 1986). From recent research we have evidence that CGAs follow the same trope and grammar as company ads and thus are not structurally different on the execution/messaging front (Muñiz and Schau 2007). Still, we cannot ignore the possibility that because of the news-worthiness of the CGA phenomenon, and the status of most CGA creators as amateurs, consumers may evaluate the quality of CGAs differently than they do traditional company ads.

As a whole, the executional quality of the CGA pool exhibits more variance than professionally-crafted ads (Thomaselli 2010), and this may establish lower quality standards for CGAs. We may therefore expect higher perceived quality judgments for CGAs than company ads because of a tendency to evaluate CGAs against these lower standards (Anderson 1973). If operative, this effect should hold across absolute quality levels, with both lower and higher executional quality CGAs being judged more favorably than comparable company-created ads. Attribute weightings may also play into heightened CGA quality judgments. From our analysis, we find that authenticity and creativity judgments figure prominently in people's attitudes toward 
CGAs, and see evidence that executional quality may be traded off for these benefits. For these reasons, we propose:

$\mathbf{H}_{4}$ : Ad quality judgments are more favorable for CGAs than for company ads.

In summary, our qualitative inquiry, along with considerations from the advertising and psychology literatures, have allowed us to develop and support a series of hypotheses regarding responses to CGAs. Overall, we have proposed that responses to CGAs are more favorable than responses to company ads across four key persuasion drivers (trustworthiness, identification, engagement, and quality perceptions). If these communication advantages are indeed supported, we should also expect that this would lead to greater persuasion as measured by $A_{a d}, A_{b r a n d}$ and purchase intent. Therefore, we also offer that:

$\mathbf{H}_{5}$ : CGAs are more persuasive than traditional company ads.

\section{STUDY 2: AN EXPERIMENT TO INVESTIGATE CGA EFFECTIVENESS}

Our first experiment tests hypotheses relating to trustworthiness $\left(\mathrm{H}_{1 \mathrm{a}-\mathrm{b}}\right)$, source identification $\left(\mathrm{H}_{2}\right)$, engagement $\left(\mathrm{H}_{3}\right)$, and overall persuasion outcomes $\left(\mathrm{H}_{5}\right)$. In a two-by-two between subjects partial factorial design, we manipulate ad source (company-ad versus CGA) and in a second nested factor we manipulate two types of creator motivations for CGAs (economic and non-economic motives). This design results in three experimental treatments that allow exploration of the relative advantages of CGAs over company ads and a probe of the moderating effects of CGA creator motivations on trustworthiness.

\section{Procedure}

A Qualtrics panel provided a national sample of 270 adults (60\% male) ranging in age from 25-55 to complete our online survey. Respondents were told that we were seeking responses to a new advertisement for the Amazon Kindle. The Kindle was chosen as the focal 
brand in light of its contemporary interest value, broad age appeal, and gender neutrality. To heighten external validity, the advertisement chosen for the study was an actual CGA created as part of a competition run by Amazon. Eligible respondents had basic familiarity of e-readers and no previous exposure to the focal ad. Thirty-seven respondents who skipped the ad or did not view it in its entirety were not included in the analysis, leaving an effective sample of 233 adults.

Based on the partial factorial design, respondents were randomly assigned to one of three experimental scenarios. In the company-created condition, they were told the ad they were about to see was created by the Avocet Communications advertising agency on behalf of their client, Amazon, who contracted with the company "to develop a campaign for its Kindle brand.” ( $\mathrm{N}=95$ ). In the CGA condition, they were told that the ad was created by a consumer: Angela Kohler. Nested within the CGA condition, in the "no economic motive" cell ( $N=89)$, subjects were told that Angela had created the ad because "she loves the Kindle so much and was looking for a way to express [her] feelings for the product and the role it plays in [her] life;" in the economic motive cell ( $\mathrm{N}=86$ ), subjects were told the ad was created "as a submission to a contest run by Amazon which promised a \$20,000 prize for the best amateur Kindle ad.” After being introduced to the advertising evaluation task, respondents were provided with a short biography of the ad creators (Avocet or Angela). We then asked respondents to view the ad.

Three platforms for generating cognitive responses were provided after the ad viewing: overall responses, responses to the ad creator, and responses to the brand. Following these openends, respondents were informed that they would answer detailed questions about the ad. The survey ended with a purchase intent question.

\section{Data and Measures}


This study leveraged a broad set of open- and closed-end dependent measures suggested in the qualitative study and supported in the literature. Trustworthiness was measured with respect to both the ad and the ad creator. Trustworthiness of the ad was measured using four items adapted from scales of advertising believability (Beltramini 1982) ("I trust what this ad has to say", "the ad is trustworthy", "the claims made in this ad are credible", "the ad felt authentic"). Trust in the creator was measured as a tripartite construct (Mayer, Davis, and Schoorman 1995;Sirdeshmukh, Singh, and Sabol 2002) and included dimensions of credibility ("Angela [Avocet] understands this brand and product category”, "Angela [Avocet] understands how people use this product”), benevolence (“Angela [Avocet] understands this brand/product category," "Angela [Avocet] cares about people who might use this product”) and integrity ("The creator of this ad is honest", "I trust the person [company] who created this ad") ( $\alpha=.94)$. Cognitive responses to the creator in the form of source bolstering and source derogation provide additional insight into trustworthiness of the source (Cacioppo and Petty 1981).

Source identification was measured using both a pictorial representation of the degree of perceived similarity and overlap between the self and creator (Bergami and Bagozzi (2000) and a semantic differential scale measuring homophily generally (“A person like me/not like me”, “somebody I can relate to/cannot relate to”, “different from me/similar to me in many ways”) and specifically (“someone with shared beliefs/values”) (McCroskey, Richmond, Daly 1975).

Overall engagement was measured with a direct probe concerning how the ad made viewers feel (7-point semantic differential anchored on disconnected-engaging). Consistent with recent research contributions (Brodie et al 2011; Calder et al. 2009), we also conceptualized and operationalized engagement as a multidimensional construct subject to context-specific contingencies. In order to ensure satisfactory face validity and because (1) measuring 
engagement is contingent on the specific context and yet (2) there do not exist specific scales to measure dimensions of consumer engagement with CGAs, we adapted and developed our own context-specific measures based on metrics for other contexts (e.g., website engagement Calder et al 2009, online shopping O’Brien and Toms 2009) and the knowledge of our own research context involving online ads.

Cognitive engagement ( $\alpha=.86)$ was measured by three items (“The ad was interesting,” “The ad kept my attention,” and “The ad was informative”). These items are adapted from and consistent with the focused attention and novelty items (e.g. “I felt interested”) in O’Brien and Toms engagement scale (2010) and also the informational/utilitarian items in Calder et al. (2009) (e.g., "the site provides information”). Cognitive engagement was also captured in the coding of thought protocols: thought counts were calculated for all response questions to indicate the amount of cognitive processing that was engaged.

Emotional engagement ( $\alpha=$.93) was measured using a four-item scale ("The ad was entertaining”, “The ad made me happy,” “The ad made me pleased,” and “The ad was a pleasure to watch”). These items are adapted from and consistent with the intrinsic enjoyment scale items in Calder et al. (2009) (e.g., “makes me happier”, “improves my mood”) and with the item "this shopping experience was fun” in O’Brien and Toms (2009).

Personal Engagement ( $\alpha=.95$ ) was measured using a four-item scale ("I connected with this ad”, “The ad highlighted aspects about the product that are good for me to know” "“The ad made me wonder what it would be like to own or use the product/brand" and "the ad message was relevant to me”). These items are adapted from and consistent with the self- and inspirationrelated items in Calder et al.’s (2009) scale (e.g., “touches me deep down”, “makes me think of things in a new way”, “makes a difference in my life”). 
Consistent with context-specification of the construct, behavioral engagement was measured along the three focal activity dimensions suggested in the qualitative study (behavioral engagement with the ad, with the ad creator, and with the brand/product). Practitioners (MarketingNPV Journal 2008) identify a wide range of possible engagement behaviors (e.g., "visiting a website", "viewing or clicking on an ad", "forwarding an ad”, "making a referral”, "requesting more information”, "blogging about a product/brand”, “opening a promotional email”, or "rating a product online”) to which Calder et al.'s (2009) scale adds select behaviors with a socializing or communal aspect (e.g., "I'm interested in receiving input from other users" or "I'd like to meet other people who visit this site"). Based on these conceptualizations and taking into account the specificities of our context, we measured behavioral engagement with the ad as the consumer's propensity to forward to the ad to others. A second five-item battery $(\alpha=.92)$ measured engagement in activities involving the creator: "willing to friend [creator] on Facebook", "willing to nominate [creator] for the national award", "interest in postings [creator's] blog”, "interest in [creator’s] ads for other brands", "interest in viewer reactions to [creator's] ads posted on YouTube.” Finally, behavioral engagement with the brand/category $(\alpha=.93$ ) was measured with a five-item scale measuring interest in "becoming a member of the Kindle Facebook community”, "receiving information about Kindle deals and coupons”, "receiving information on Kindle trial programs", "reviews for the Kindle” and "reviews for competitors to the Kindle”.

As indicators of overall ad effectiveness, traditional operationalizations for $\mathrm{A}_{\mathrm{ad}}$ and $\mathrm{A}_{\text {brand }}$ were used (MacKenzie, Lutz, and Belch 1986; Shimp 1981). Persuasion was also measured among e-book non-owners through the change in purchase interest measured at the beginning of the study and at the end of the study. 


\section{Results}

We find support for $\mathrm{H}_{1 \mathrm{a}}$ : CGAs and their creators are seen as more trustworthy than company-ads and their creators. Respondents felt the CGA ads were more authentic and made claims that were more credible and trustworthy than the company ad (scale means: $\mathbf{M}_{\mathrm{CGA}}$ $\left.=5.29, \mathrm{M}_{\text {Company }}=4.80, F(1,231)=5.92, p<.05\right)$. Trust in the ad creator was also significantly higher in the CGA condition $\left(\mathrm{M}_{\mathrm{CGA}}=5.40, \mathrm{M}_{\text {Company }}=4.77, F(1,231)=14.18, p<.001\right)$. This effect held across all trust dimensions including ability $\left(\mathrm{M}_{\mathrm{CGA}}=5.32, \mathrm{M}_{\text {Company }}=4.68, F(1,231)=10.06\right.$, $p<.001)$, integrity $\left(\mathrm{M}_{\mathrm{CGA}}=5.35, \mathrm{M}_{\text {Company }}=4.79, F(1,231)=11.30, p<.01\right)$ and benevolence $\left(\mathrm{M}_{\mathrm{CGA}}=5.53, \mathrm{M}_{\text {Company }}=4.85, F(1,231)=14.72, p<.001\right)$. The effect of trust was also reflected in cognitive responses about the ad creator. Respondents were more likely to bolster the source in the CGA condition, generating more positive creator-related thoughts $\left(\mathrm{M}_{\mathrm{CGA}}=0.80, \mathrm{M}_{\mathrm{Company}}=\right.$ 0.36, $F(1,195)=20.18, p<.001)$.

We did not find support for $\mathrm{H}_{1 \mathrm{~b}}$ : CGA creator motives did not affect perceived trustworthiness and credibility of the ad. Pretests using the Tukey HSD at the .05 level confirmed the attribution of economic versus non-economic motives in the test conditions. Specifically, respondents (1) perceived the creator's motives as driven by sincere brand attachment in the organic CGA scenario $\left(\mathrm{M}_{\mathrm{NoEconomicMotive}} \mathrm{CGA}=5.40\right)$ when compared to both the competition CGA $\left(\mathrm{M}_{\text {Economic MotiveCGA }}=4.06\right)$ and company ad scenarios $\left(\mathrm{M}_{\text {Company }}=4.21\right)$, which did not differ, and $(2)$ rated the creator as higher $(\mathrm{p}<.05)$ in monetary motivation in both the company $\left(\mathrm{M}_{\text {Company }}=6.17\right)$ and CGA competition scenario $\left(\mathrm{M}_{\text {EconomicMotiveCGA }}=5.71\right)$ when compared to the organic CGA scenario $\left(\mathrm{M}_{\mathrm{NoE} \text { conomicMotive CGA }}=3.93\right)$. However, these perceived motivational differences did not affect viewers' trust in the creator or his/her ad. Contrary to our hypothesis, we found no significant differences between the CGA conditions in the trustworthiness of the ad 
$\left(\mathrm{M}_{\text {NoEconomicMotive CGA }}=5.14, \mathrm{M}_{\text {EconomicMotiveCGA }}=5.42, \mathrm{~F}(1,157)=1.70, \mathrm{p}=0.20\right)$ or the trustworthiness of the creator $\left(\mathrm{M}_{\text {NoEconomicMotive CGA }}=5.34, \mathrm{M}_{\text {EconomicMotiveCGA }}=5.45, \mathrm{~F}(1,157)=\right.$ $0.42, \mathrm{p}=0.52)$. Irrespective of the creator's motives, both types of CGAs were trusted to the same degree, and both CGAs were more trusted than the company ads. Nor did we find evidence of a moderating impact of CGA motives on other dependent measures including persuasion $\left(A_{a d}\right.$, $A_{\text {brand, }}$ purchase intent), engagement (cognitive, emotional, personal, behavioral), or source identification. The attribution of creator motives in no way drives results.

Hypothesis $\mathrm{H}_{2}$, which proposes that viewer-creator identification drives CGA advantages, was also not supported. No significant differences between CGA and company ads were found using the pictorial measure of identification $\left(\mathrm{M}_{\mathrm{CGA}}=3.53, \mathrm{M}_{\mathrm{Company}}=3.14, F(1,231)=1.70\right.$, $\mathrm{p}=0.19)$ or the scalar homophily metric $\left(\mathrm{M}_{\mathrm{CGA}}=4.39, \mathrm{M}_{\text {Company }}=4.19, F(1,231)=0.84, \mathrm{p}=0.36\right)$.

Engagement results were strong but in the case of behavioral engagement, were confined to select aspects of the construct. In support of $\mathrm{H}_{3}$, respondents in the CGA condition felt they were significantly more engaged than those viewing company ads using the disconnectedengaging metric $\left(\mathrm{M}_{\mathrm{CGA}}=5.30, \mathrm{M}_{\text {Company }}=4.69, F(1,231)=5.7, p<0.05\right)$. There was a significant main effect of ad source on cognitive engagement $\left(\mathrm{M}_{\mathrm{CGA}}=5.19, \mathrm{M}_{\text {Company }}=4.62, F(1,231)=6.96\right.$, $p<0.01)$, emotional engagement $\left(\mathrm{M}_{\mathrm{CGA}}=5.59, \mathrm{M}_{\text {Company }}=4.94, F(1,231)=10.63, p<0.01\right)$ and personal engagement $\left(\mathrm{M}_{\mathrm{CGA}}=4.63, \mathrm{M}_{\text {Company }}=4.13, F(1,231)=4.20, p<0.05\right)$. Additional evidence of enhanced cognitive engagement for CGAs over company ads was obtained through an analysis of cognitive responses: more thoughts were generated in the CGA condition than in the company condition $\left(\mathrm{M}_{\mathrm{CGA}}=4.34, \mathrm{M}_{\mathrm{Company}}=2.99, F(1,231)=3.43, p=0.06\right)$ and more creatorrelated thoughts were generated for CGAs versus company ads $\left(\mathrm{M}_{\mathrm{CGA}}=1.09, \mathrm{M}_{\text {Company }}=0.90, F(1\right.$, $231)=4.18, p<0.05$ ). We also find that CGAs engender more behavioral engagement involving 
ad creators $\left(\mathrm{M}_{\mathrm{CGA}}=3.95, \mathrm{M}_{\text {Company }}=3.50, F(1,231)=4.72, p<.05\right)$. We did not find evidence of increased behavioral engagement involving the brand $\left(\mathrm{M}_{\mathrm{CGA}}=3.75, \mathrm{M}_{\text {Company }}=3.74, F(1,231)=\right.$ $.001, p=.972)$ or the ad $(\chi 2=.73, p=.43$ for forwarding the ad).

Although testing the possible role of engagement as an antecedent of ad response was not a focus of our study design or hypotheses, we provide insight into this question using the correlational approach reported in Calder et al.'s (2009) exploration of the construct. All correlations between all forms of engagement (cognitive, personal, behavioral, and emotional) and ad performance $\left(\mathrm{A}_{\mathrm{ad}}, \mathrm{A}_{\mathrm{brand}}\right.$, purchase intent) were positive and highly significant $(\mathrm{p}<.01)$, indicating that engagement is positively related to ad effectiveness. These results replicate Calder et al. (2009) and provide correlational evidence of the engagement $\rightarrow$ persuasion link.

Finally, we obtain support for $\mathrm{H}_{5}$ : CGAs outperform company ads in terms of persuasion outcomes. We found a significant main effect of source condition on attitudes toward both the ad $\left(\mathrm{M}_{\mathrm{CGA}}=5.73, \mathrm{M}_{\text {Company }}=4.80, F(1,231)=17.54, p<.001\right)$ and the Kindle brand $\left(\mathrm{M}_{\mathrm{CGA}}=\right.$ $\left.5.67, \mathrm{M}_{\text {Company }}=5.30, F(1,231)=4.38, p<.05\right)$. More positive brand attitudes were also reflected in cognitive responses. Respondents listed more positive brand related thoughts in the CGA condition than in the company condition as indicated by the mean valence of total thoughts $\left(\mathrm{M}_{\mathrm{CGA}}\right.$ $\left.=0.53, \mathrm{M}_{\text {Company }}=0.15, F(1,187)=10.67, p<.01\right)$. A repeated measures analysis revealed a significant increase in purchase intent for those in the CGA condition $\left(\mathrm{M}_{\text {Before }}=3.74, \mathrm{M}_{\mathrm{After}}=4.16\right.$, $t, 125=3.52, \mathrm{p}<.001)$ but not for those in company-as-source cell $\left(\mathrm{M}_{\text {Before }}=3.60, \mathrm{M}_{\text {After }}=3.65, t\right.$, $51=0.28, p=0.78$ ). This evidence is strong: CGAs are more persuasive than company ads.

Results consistently support enhanced effectiveness for CGAs versus traditional company ads. The persuasive benefits of CGA derive from their capacity to engage consumers on cognitive, emotional, and personal levels, with the venue offering increased avenues for 
behavioral interactions with ad creators. The role of the creator is also reflected in enhanced judgments of credibility and trustworthiness that drive favorable responses and stand strong in the face of tainted creator motives. The creator is not an all-powerful factor: identification with the source does not drive CGA reception. This results pattern suggests that it is the simple fact that CGAs are made by consumers and not companies that is at issue in CGA response.

\section{STUDY 3: UNDERSTANDING AD QUALITY AND ITS ROLE IN CGA EFFECTS}

In this two-part study, we seek to understand if CGAs are judged more favorably on ad quality criteria and why. In a lab experiment (Study 3a), we first explore how ad-quality judgments differ for CGAs and company ads. A follow-on study (Study 3b) involves a survey with a national sample to provide insight into the mechanisms driving this effect.

\section{Design and Procedure: Study 3A}

Study 3a was designed to test whether consumers evaluate the quality of CGAs differently $\left(\mathrm{H}_{4}\right)$, thus systematically affecting their advertising outcomes $\left(\mathrm{H}_{5}\right)$. The experiment also strengthens external validity by providing a replication and extension of Study 2 results with a different sample using a second product category and for a different brand.

The experiment involved a 2 (source condition: ad identified as CGA versus no source given) X 2 (high versus low executional quality of the ad) between-subjects design. A total of 196 undergraduate business students aged 18-22 who received course credit for participation comprised the sample. The Toyota Yaris was chosen as the focal brand in light of its newness on the market and relevance to student subjects. Respondents were brought to a central testing facility where they viewed the ad as a group (25 respondents per session) on a projector screen. Subjects then completed a paper and pencil survey regarding brand attitudes and behaviors, cognitions, engagement levels, and advertising response profiles. 
We selected four 30-second Yaris CGAs from a total of 30 available commercials posted on CurrentTV and YouTube. To guide our decisions, four judges reviewed the ads and rated them on executional quality (7-point scales, low to high) and informational content (7-point scales, low to high). Ad selection was attentive to a need for realism in the chosen ads. Specifically, chosen ads need to be neither so poor that viewers would never believe that a company could be behind them, nor so technically-superior that people would not believe that an amateur could be the creator. Means on measures of executional quality for the chosen ads were thus in the middle, ranging from 2.87-4.34 on a 7-point scale. Selected ads yielded sufficient variation for tests of our hypotheses. A pretest confirmed the choice of two ads with high brand message content and two with low content $(F 4,119=20.48, \mathrm{p}<.001)$, and two ads with high perceived executional quality characteristics and two with low perceptions of the quality (F4,119 $=6.70, \mathrm{p}<.001)$. The operationalization above provides a stronger test of theory given the constricted quality range.

Respondents were randomly assigned to view one of the four ads, and were either told that the ad they were about to see was created by a consumer $(\mathrm{N}=99)$ or given no information concerning the source of the ad (N=97). These two source conditions, “consumer-created” and “no source,” provided a natural test of our hypotheses by replicating the normal viewing environment: with traditional ads, people are not told the ad they are about to see was created by a company or its agency, whereas consumer-generated ads are typically identified as being crafted by ordinary people. This design also provided a stronger test for results from Study 2: if CGAs still outperform "no source” ads then any boost in perceived performance can be 
attributed solely to the ad being labeling as a CGA, rather than any heightened critical evaluation when company or agency is highlighted as the source. ${ }^{1}$

\section{Results from Study 3A}

As validation of Study 2 results, CGAs again lead to stronger persuasion outcomes than company ads $\left(\mathrm{H}_{5}\right)$. Respondents who were told the ad was consumer-generated had more positive $\mathrm{A}_{\mathrm{ad}}\left(\mathrm{M}_{\mathrm{CGA}}=4.59, \mathrm{M}_{\mathrm{NS}}=4.10 F(1,194)=4.78, p<.05\right)$, more positive $\mathrm{A}_{\text {brand }}\left(\mathrm{M}_{\mathrm{CGA}}=\right.$ 4.32, $\left.\mathrm{M}_{\mathrm{NS}}=3.99, F(1,194)=3.47, p=.08\right)$, higher brand interest $\left(\mathrm{M}_{\mathrm{CGA}}=2.65, \mathrm{M}_{\mathrm{NS}}=1.88, F(1\right.$, $194)=13.75, p<.001)$ and stronger purchase intent $\left(\mathrm{M}_{\mathrm{CGA}}=2.72, \mathrm{M}_{\mathrm{NS}}=2.08, F(1,194)=9.42\right.$, $p<.05)$ than those in the no source condition.

Results provide strong support for $\mathrm{H}_{4}$ : ad quality judgments are more favorable for CGAs than for company ads. When the ad was identified as a CGA, respondents evaluated it as being of higher executional quality $\left(\mathrm{M}_{\mathrm{CGA}}=4.12, \mathrm{M}_{\mathrm{NS}}=3.71, F(1,194)=5.82, p<.05\right)$. This overall boost in perceived executional quality for CGAs held at all ad quality levels: the interaction between ad quality and ad source was not significant $(F(1,194)=2.25, p>.1)$. In other words, the quality of CGAs was perceived to be higher regardless of whether the ad was of high or low quality as rated by experts. These results are consistent with traditional ad response models linking higher executional quality to higher $\mathrm{A}_{\mathrm{ad}}$ and $\mathrm{A}_{\text {brand }}$ (MacKenzie, Lutz, and Belch 1986).

\section{Study Design and Procedure: Study 3B}

A follow-up study was conducted to investigate potential drivers and moderators of the above quality perception effects. Since we manipulated ad source and found evidence of a perceived quality boost at all execution quality levels, we speculate, using the insights from our

\footnotetext{
${ }^{1}$ A pretest confirmed our assumption that reactions to "no source identified" ads were identical to ads attributed to a company or ad agency. Attributions of who the ad creator was were identical on outcome measures $\left(A_{b r a n d}, A_{a d}\right)$.
} 
qualitative inquiry, that one reason for the boost involves lower quality expectations for CGAs than for company ads. This "lower quality bar" explanation is consistent with an expectationdisconfirmation theoretical framework (Anderson 1973). Another possibility also supported in the qualitative Study 1 is that consumers use different criteria when judging CGAs or that they give different weights to these criteria: in other words, a trade-off of some sort is operative in making ad quality judgments. Finally, of concern is whether the benefits of perceived quality erode with a person's increased familiarity with CGAs. This is an important area of inquiry as some CGA critics contend that the so-called CGA advantage is short-lived and can be explained away through novelty effects (Thomaselli 2010). Thus, this follow-up survey explores: (1) if consumers have different expectations for CGA and company ads (i.e., a potential "lowering of the bar” for CGAs); (2) if consumers trade-off different aspects when evaluating CGAs and company ads (e.g. authenticity for execution quality); and (3) if judgments and expectations of CGA change based on familiarity with the CGA phenomenon (i.e., a novelty wear out effect).

An online survey was conducted with 200 members (119 males and 81 females) of a national online panel (Amazon MTurk). Participants were compensated with a small monetary incentive for their participation. The sample was predominantly Caucasian (86.5\%), with AsianAmericans (11\%) African-American (4.5\%), and Hispanic-American (4.5\%) representation. The average age was 30.2 years, and for $95 \%$ of the respondents, English was the native language.

The introduction to the survey indicated that we were interested in opinions about different types of advertisements. We provided a quick definition of two focal ad types: "Company-Created Ads" and "Consumer-Created-Ads" and used these two terms throughout the questionnaire. In the first section of the questionnaire, participants were asked to imagine that they were about to watch a company-created ad and a consumer-created-ad, and think about their 
expectations for each type. We provided respondents with a list of advertisement evaluative attributes and asked them to move a slider to the right or the left to indicate the extent to which they thought that "Company-created ads are better" or "consumer-created ads are better" on each of the attributes. The middle point was the default starting position for the slider and it was anchored with "neither one is better than the other". Although not directly visible to the respondents, the slider scale generated scores ranging from -50 (company ads are better) to +50 (CGA are better). Expectations were assessed for 17 different evaluative quality attributes plus one overall assessment measure. The items (see Figure 1) were adapted based on measures used in previous advertising studies (Batra and Ray 1986; Belch and Belch 1984; Derbaix 1995; MacKenzie, Lutz, and Belch 1986; Singh, Slotkin, and Vamosi 2007). The next section asked respondents to indicate how important each of these 17 attributes were in judging how good or bad a company-created (consumer-created) ad was (a total of thirty-four 5-point scales ranging from “extremely unimportant” to “extremely important”).

Additional items provided alternate measures of perceived ad quality. Respondents indicated (using a fixed sum scale) the percentage of company-created ads (consumer-created ads) that they thought were "high", "medium” or "low" quality. They also answered a series of nine likert questions concerning opinions about company and consumer-created ads (e.g., direct assessments of how they evaluate the ads, what standards they apply, what criteria they are willing to trade-off). Respondents also answered seven questions tapping previous exposure to consumer created-advertising (i.e., Before this survey, I was already familiar with the phenomenon of Consumer Created Advertisements; Are you familiar with contests that have been run to generate Consumer Created Advertisements? Did you know that Consumer Created Ads have been aired during the last four Super Bowls? Have you read information or articles 
about Consumer Created Ads? Have you seen Consumer Created Ads aired during regular TV programs? Have you seen Consumer Created Ads on YouTube or other online video-sharing sites? Have you discussed the topic of Consumer Created Ads with friends or acquaintances?). Demographic information was collected at the survey close.

\section{Results of Study 3B}

Results from the single item measuring overall quality expectations confirmed that respondents expected company ads to be better than CGAs $(\mathrm{M}=-24.81$, $\mathrm{t} 199=17.83, \mathrm{p}<.001)$. Respondents indicated that they expected a greater percentage of high quality ads for company ads $\left(\mathrm{M}_{\text {Company }}=50.0 \%\right)$ compared to CGAs $\left(\mathrm{M}_{\mathrm{CGA}}=25.7 \%\right.$, $\left.\mathrm{t} 199=9.47<.001\right)$, and that a greater percentage of CGAs would be low quality ( $\left.\mathrm{M}_{\mathrm{CGA}}=35.4 \%\right)$ versus company ads ( $\mathrm{M}_{\text {Company }}=20.0 \%$, t199=10.82, p<.001). As shown in Figure 1, respondents indicated that on all but one attribute (Storyline/Script Quality), they had different quality expectations for CGA and company ads. --Insert Figure 1 Here

In order to focus our analysis and identify the different facets in the above set of expectations, we conducted an exploratory factor analysis on the 17 evaluative attribute items. The rotated solutions (both Varimax and Oblimin) confirmed that the items loaded on three different factors. Factor I (Executional Quality) was comprised of ten items (Production Professionalism, Technical Sophistication, Quality of Lighting, Quality of Sound, Quality of Video/Photography, Quality of Video Editing, Execution Quality, Quality of Acting/Animation, Quality of Colors, and Quality of Music; $\alpha=.90$ ). Factor II (Artistic Originality) was comprised of four items (Storyline/Script Quality, Artistry, Creativity of the Ad, Uniqueness of the Ad; $\alpha=.74$ ). Factor III (Authenticity) was comprised of three items (Realism of the Ad, Authenticity of 
the Ad, and Trustworthiness of the Ad, $\alpha=.79)$. In the remaining analyses, we use scores based on scale averages for these factors.

Overall, respondents expect company ads to be better on executional quality $(\mathrm{M}=-24.50$, t199=25.45, $\mathrm{p}<.001)$, and CGAs to be better on artistic originality $(\mathrm{M}=10.71, \mathrm{t} 199=8.76, \mathrm{p}<.001)$ and authenticity $(\mathrm{M}=17.94, \mathrm{t} 199=12.97, \mathrm{p}<.001)$. We also found that respondents agreed (i.e., mean above neutral midpoint) with the following two statements suggesting a lower bar for CGAs: "I apply lower standards when judging the quality of Consumer Created Ads than I would when judging Company Created Ads" (M=3.75, t199=9.93 p<.001) and "In general, I do not evaluate Consumer Created Ads as critically as I do Company Created Ads” (M=3.70, t198=9.34 $\mathrm{p}<.001)$. Together this first set of results provides confirmation that consumers have different expectations for CGAs than for company ads and in particular, they have lower executional quality expectations for CGAs.

We also found evidence that consumers make different attribute trade-offs when judging the quality of CGAs versus company ads. Our results show that executional quality is more important when judging company ads $\left(\mathrm{M}_{\text {Company }}=4.15\right)$ than when judging $\mathrm{CGAs}\left(\mathrm{M}_{\mathrm{CGA}}=3.42\right.$, $\mathrm{t} 199=3.27, \mathrm{p}<=.001)$. However, artistic originality $\left(\mathrm{M}_{\mathrm{CGA}}=4.28\right)$ and authenticity $\left(\mathrm{M}_{\mathrm{CGA}}=4.18\right)$ are more important criteria for CGAs than for company ads $\left(\mathrm{M}_{\text {Company }}=3.95, \mathrm{t} 199=5.38, \mathrm{p}<.001\right.$; $\left.\mathrm{M}_{\text {Company }}=3.97, \mathrm{t} 199=12.71, \mathrm{p}<.001\right)$. Also, consumers agreed that they were "willing to trade-off execution quality to get the authenticity of Consumer Created ads” (M=3.89, t199=13.37 $\mathrm{p}<.001$ ), and that they were less "willing to overlook mistakes made in producing the ad" "when judging how good or bad a Company Created Ad is” than for a CGA $\left(\mathrm{M}_{\text {Company }}=2.29, \mathrm{M}_{\mathrm{CGA}}=3.89\right.$, t199=15.4 $\mathrm{p}<.001)$. This set of results supports that consumers trade off executional quality for 
artistic originality and authenticity and that they apply a forgiveness factor when evaluating the technical quality of CGAs.

Our last set of results investigate the potential moderating effect of CGA novelty; in other words, whether or not quality judgments and expectations change based on prior exposure to and familiarity with CGAs. Based on answers to the 7-item CGA familiarity battery, we identified two clusters of respondents using SPSS's two-step clustering routine. Analysis confirmed that one cluster ( $n=82)$ had a higher level of familiarity with CGAs than the second cluster $(n=118)$ ( $<<.001$ for each item). We then reanalyzed quality expectations, attribute importance ratings, and the answers to the other opinion measures based on these cluster memberships. We found that increased familiarity for the CGA phenomenon did not impact any of the results reported above regarding expectations, trade-offs, or the relative importance of attributes except for one item: expectations of artistic originality. Although people placed the same importance on artistic originality regardless of their exposure levels, consumers with high CGA familiarity had greater expectations for this facet of advertising quality $\left(\mathrm{M}_{\text {Hifam }}=14.59\right)$ than did low CGA familiarity respondents $\left(\mathrm{M}_{\mathrm{LoFam}}=8.01, \mathrm{t} 199=7.22 \mathrm{p}<.01\right)$. In other words, increased CGA familiarity actually strengthened expectations that CGAs are more creative and artistically original than company ads. The data therefore show no evidence of CGA wear-out due to higher exposure: there is no leveling-off of the CGA effect with increased familiarity with CGAs. We conclude that despite increased proliferation of the tactic over the past several years, consumers continue to judge CGAs differently than company ads.

\section{DISCUSSION AND FUTURE RESEARCH}

Our four-part multi-method research program provides reinforcing support for the differential effectiveness of CGAs versus company ads. Although we find evidence for the 
operation of many of the same mechanisms known to drive persuasion with traditional advertising, some interesting differences are noted. We find that CGAs are viewed as being of higher quality than traditional ads regardless of actual quality levels. This effect is derived in part from lower ingoing expectations concerning the quality of ads made by consumers. The CGA quality boost further derives from differential weights concerning the attributes used to make quality judgments. We find that executional quality factors play less a role in judging CGA quality while authenticity and creativity are rated as more important: people apply a forgiveness factor when judging CGA quality and make trade-offs against creativity and authenticity when forming their impressions. Preliminary evidence denies the operation of wear-out in diminishing perceived quality advantages: despite experience with this ad form, the CGA quality differential and the biased perceptions that support it stand strong.

Our multi-method inquiry also supports a widespread contention among practitioners employing CGA strategies: CGAs engage viewers more on cognitive, personal, emotional and behavioral grounds. Of particular note is a role for engagement with the ad creator, including creator-viewer relationship building as well as increased cognitive reflection on the creator and the production processes s/he used to produce the ad. Source-related benefits also manifest in trustworthiness advantages for CGAs, not only in terms of typically-considered source credibility issues, but also the perceived authenticity and benevolence of the source as well. The trustworthiness advantage is strong and creator motivations for profit do not dilute it. In other words, people do not care if a CGA is created for personal gain: what they are interested in is that the ad came from a consumer instead of the company. Results also suggest that it is not personal identification with a CGA source judged to be similar in lifestyles or values that drives 
CGA effectiveness. What drives CGA persuasion advantages is the simple presence of a discernible, credible, authentic, and engaging non-corporate, consumer source.

Our results have important implications for advertising theory and research. CGAs, by their very definition, incorporate ad creators as additional stakeholders in the usual viewer-ad-brand triad and our theories of advertising effectiveness do not adequately consider the role of and processes involving the people behind the ad. As the source behind the ad becomes a topic for rumination, understanding how people draw source inferences becomes critical. Underdog effects (Paharia et al. 2011) may drive CGA source advantages such that people become engaged with CGAs not as advertising stimuli but because of what they represent (i.e., the triumph of the 'little guy'). Practitioners like Ann Mukherjee of Frito-Lay understand that creator stories are an important part of CGA campaigns: "It was about those two guys. They were the heroes of our story, that's what people were ecstatic about.” (Wong 2009, p. 1). Research must consider how advertising works when the ad incorporates a narrative storyline to showcase the creator rather than serving simply as a focal communication in itself (Deighton, Romer, and McQueen 1989).

More generally, as the story behind the creation of the ad becomes equally or more important than the ad, a new construct—attitude-towards-the-creator $\left(\mathrm{A}_{\text {creator }}\right)$ —emerges as a needed complement to familiar concepts of $\mathrm{A}_{\text {ad }}$ and $\mathrm{A}_{\text {brand. }}$. Research can investigate the relative effectiveness of different tactics designed to showcase the ad creator: is $\mathrm{A}_{\text {creator }}$ maximized when the creator is personally identified and contextualized, for example, or when s/he is framed more generally as a non-company, non-industry source? The humanizing of advertising through identifiable, personalized and relatable creators also grants consumers additional roles beyond those of simple ad critics, including, as our qualitative data shows us, roles as supportive relationship partners and friends. What are these viewer-creator roles and how do they drive 
CGA effectiveness? Theories of trust, authenticity and source credibility provide an important piece in this puzzle. While qualitative work by Ertimur and Gilly (2011) suggests CGA trustworthiness benefits derived only from authenticity credentials, we find a strong differential effect for credibility/ability as well.

Results also have important implications for advertising practice. Within the CGA paradigm, ad executives are tasked not with creating ad content but rather facilitating an authentic and engaging consumer voice for the brand. Important managerial decisions revolve around sourcing processes for organic CGA content and, vis-à-vis competitions, how these will be designed and promoted, how winning ads will be selected, how creators will be showcased, and where and when submissions and winning ads will be shown. As advertising moves past the ad to the broader storyline that incorporates ad creators and their production processes, managerial roles must shift in kind. Our findings point to the need to better understand the ad creation/sourcing process so as to help managers in this new role. In our data, active debates were waged concerning CGAs' selection processes (e.g., via unanimous vote, expert panel, or community response) and the evaluations of fairness these processes raise. Which process is more effective? Theories of consumer creativity (Moreau and Dahl 2005) can provide templates for examining CGA design opportunities. For example, Chevy provided a toolbox for easy CGA creation while Firefox and Converse offered no creativity constraints. As managers broaden their roles as facilitators, how should CGAs best be sourced for the brand? CGA competitions also bring in multiple ad creators, each with a different brand voice, thus encouraging higher levels of meaning negotiation. Research can consider implications of this multi-vocal brand.

Our results unanimously favor CGAs and these findings may grant laggard companies the confidence to add CGAs to their strategic mix. Still, though we find no such evidence, we offer 
caution in the wide scale adoption of CGA until dedicated studies of wear out can be designed. A bandwagon effect would threaten CGA advantages: the perceived quality boost, enhanced trustworthiness, authenticity credentials and deeper engagement. If CGA contests proliferate such that high quality company-sponsored ads by pseudo-professionals dominate the CGA landscape, then expectations of CGA quality should rise in kind, negating the benefits of evaluation against lowered standards. Trust and authenticity could also weaken as the line between "real people” and advertising agencies blurs. As the practice of CGA spreads and companies seek new and different ways to engage consumers, ethical breaches also threaten the trust advantage. Consider not only recent moves by companies to create fake consumer copy (e.g. McDonald's and their faked lincolnfry.com/ blog), but also the behavior of activists who stage bogus CGA competitions in efforts to discredit brands (e.g. Greenpeace's Shell spoof at ArticReady.com). Increased exposure can reduce perceived CGA novelty and limit their ability to break through the advertising clutter. Further, if CGAs are re-framed in people's minds as persuasion attempts rather than engaging consumer-created content, the schemer schema (Wright 1986) may negate CGA's positive effects. Given that CGA benefits are herein shown to be perceptual rather than actual, the mechanisms behind a possible reframing are especially deserving of future research. Only longitudinal study designs with appropriate time series analyses can provide definitive insight into wear out effects explored here on a cross-sectional survey basis. The study of wear out for a class of ads, CGAs, versus a traditional wear out study for a particular advertisement presents an exciting area of future research.

Our inquiry study is not without its limitations, and these also offer platforms for future research. We base our hypotheses on a qualitative analysis of YouTube data and yet this data collection site presents potential concerns: biased viewership, a cursory level of involvement, a 
user base primed to interact and co-create, and a preponderance of banal and base commentary. Strategically, one can augment YouTube data with additional sites or conduct multi-method inquiry, as we do. One important avenue for future research is developing an understanding of CGA effectiveness in different media and execution environments. How does commentary and engagement differ on video sharing sites such as YouTube versus company forums or other social media, for example? Is engagement different when the ad is hosted on the internet versus aired on television? Second, although the CGAs we evaluated in the qualitative spanned creative styles and genres, and both humorous and informational ads were included in experiment Study 3, we have not systematically tested for creative strategy effects. Future research can determine whether the same techniques known to generate favorable consumer evaluations (e.g., humor) hold for consumer-generated content, and whether the CGA advantage holds above known strategy effects. Third, we examined only successful CGAs in study 1 and thus the persuasive benefits and engagement levels that we observed may be limited to these successful CGAs. Based on our findings from Study 3b, certain characteristics (e.g. creativeness) may differentially impact CGA and company created ad reception. Future work should examine the moderating role of such characteristics on CGA persuasiveness.

Our study designs are also limited in their ability to inform process, and this stands as a necessary extension of this research. Future work can provide comparative tests of the relative effectiveness of our various mechanisms and possible causal links between them (e.g., $\mathrm{A}_{\text {creator }} \rightarrow$ engagement $\rightarrow$ persuasion; engagement cognitive $\rightarrow$ engagement $_{\text {behavioral }} \rightarrow$ persuasion) Although engagement was not the focus of this inquiry, findings show promise in a focused context-sensitive exploration of this construct in the CGA realm. Our qualitative work points to the operation of a complex set of relationships within the YouTube community and between ad 
creators and posters, and netnography can usefully explore this social engagement idea. Advance of the engagement theoretic agenda will also require dedicated scale development activity to usefully inform this line of research. 
Figure 1

\begin{tabular}{|c|c|c|}
\hline Advertising Attribute & Attribute Ex & \\
\hline & $\begin{array}{l}\text { Company Ads } \\
\text { are better }\end{array}$ & $\begin{array}{r}\text { Consumer Ads } \\
\text { are better }\end{array}$ \\
\hline Production Professionalism (I) & -32.27 & \\
\hline Technical Sophistication (I) & -28.38 & \\
\hline Quality of Lighting (I) & -27.66 & \\
\hline Quality of Sound (I) & -26.60 & \\
\hline Quality of Video/Photography (I) & -26.24 & \\
\hline Quality of Video Editing (I) & -24.13 & \\
\hline Execution Quality (I) & -22.51 & \\
\hline Quality of Acting/Animation (I) & -22.28 & \\
\hline Quality of Colors (I) & -17.76 & \\
\hline Quality of Music (I) & -17.19 & \\
\hline Storyline/Script Quality (II) & -0.75 & \\
\hline Artistry (II) & 4.29 & \\
\hline Realism of the $\mathrm{Ad}$ (III) & 15.39 & \\
\hline Creativity of the Ad (II) & 16.77 & \\
\hline Authenticity of the Ad (III) & 18.03 & \\
\hline Trustworthiness of the Ad (III) & 20.42 & \\
\hline Uniqueness of the Ad (II) & 22.53 & \\
\hline
\end{tabular}

Note: Three factors (I: Executional Quality; II: Artistic Originality, and III: Authenticity) comprise the overall scale.

All items are statistically different from zero $p<.001$ except Artistry $(p=.01)$.

Storyline/Script Quality is non-significant $(p=.67)$. 


\section{REFERENCES}

Anderson, Rolph E. 1973. “Consumer Dissatisfaction: The Effect of Disconfirmed Expectancy on Perceived Product Performance.” Journal of Marketing Research 10: 38-44.

Batra, Rajeev, and Michael L. Ray. 1986. “Affective Responses Mediating Acceptance of Advertising.” Journal of Consumer Research: 234-249.

Belch, George E., and Michael A. Belch. 1984. "An Investigation of the Effects of Repetition on Cognitive and Affective Reactions to Humorous and Serious Television Commercials.” Advances in Consumer Research 11 (1): 4-10.

Beltramini, Richard F. 1982. “Advertising Perceived Believability Scale.” Ed. R.F. Corrigan, F.B. Kraft, and R.H. Ross. Proceedings of the Southwestern Marketing Association 1: 13.

Bergami, Massimo, and Richard P. Bagozzi. 2000. "Self-Categorization, Affective Commitment and Group Self-esteem as Distinct Aspects of Social Identity in the Organization.” British Journal of Social Psychology 39 (4): 555-577.

Berthon, Pierre, Leyland Pitt, and Colin Campbell. 2008. "Ad Lib: When Customers Create the Ad.” California Management Review 50 (4): 6-30.

Beverland, Michael B., and Francis J. Farrelly. 2010. “The Quest for Authenticity in Consumption: Consumers’ Purposive Choice of Authentic Cues to Shape Experienced Outcomes.” Journal of Consumer Research 36 (5): 838-856.

Bickart, Barbara, and Robert M. Schindler. 2001. "Internet Forums as Influential Sources of Consumer Information.” Journal of Interactive Marketing 15 (3): 31-40.

Brock, Timothy C. 1965. “Communicator-recipient Similarity and Decision Change.” Journal of Personality and Social Psychology 1 (6): 650-654.

Brodie, Roderick J., Linda D. Hollebeek, Biljana Juric’, and Ana Illic’. 2011. “Customer Engagement: Conceptual Domain, Fundamental Propositions, and Implications for Research.” Journal of Service Research 14 (3): 252-271.

Burstein, David D. 2012. "5 Lessons in Participatory Marketing from Doritos' 'Crash The Super Bowl' and CMO Ann Mukherjee.” FastCompany's Co.Create. http://www.fastcocreate.com/1679605/5-lessons-in-participatory-marketing-from-doritoscrash-the-super-bowl-and-cmo-ann-mukherjee.

Busch, Paul, and David T. Wilson. 1976. “An Experimental Analysis of a Salesman's Expert and Referent Bases of Social Power in the Buyer-seller Dyad.” Journal of Marketing Research 13 (1): 3-11.

Cacioppo, John T., and Richard E. Petty. 1981. "Social Psychological Procedures for Cognitive Response Assessment: The Thought Listing Technique.” In Cognitive Assessment, ed. T.V. Merluzzi, C. R. Glass, and M. Genest, 309-342. New York: Guilford Press.

Calder, Bobby J., Edward C. Malthouse, and Ute Schaedel. 2009. “An Experimental Study of the Relationship Between Online Engagement and Advertising Effectiveness.” Journal of Interactive Marketing 23 (4): 321-331.

Campbell, Collin, Leyland F. Pitt, Michael Parent, and Pierre R. Berthon. 2011. "Understanding Consumer Conversations Around Ads in a Web 2.0 World.” Journal of Advertising 40 (1): 87-102.

Cheong, Hyuk Jun, and Margaret A. Morrison. 2008. "Consumers' Reliance on Product Information and Recommendations Found in UGC.” Journal of Interactive Advertising 8 (2): $1-29$. 
Creamer, Matthew. 2007. "Ad Agency of the Year: The Consumer.” Advertising Age, January 8.

Daugherty, Terry, Matthew S. Eastin, and Laura Bright. 2008. "Exploring Consumer

Motivations for Creating User-generated Content.” Journal of Interactive Advertising 8

(2): $1-24$.

Deighton, John. 2008. “Dove: Evolution of a Brand.” Harvard Business School Case (9-508047).

Deighton, John, and Leora Kornfeld. 2009. “Interactivity’s Unanticipated Consequences for Marketers and Marketing.” Journal of Interactive Marketing 23 (1): 4-10.

—. 2010. “United Breaks Guitars.” Harvard Business School Case (510-057).

Deighton, John, Daniel Romer, and Josh McQueen. 1989. “Using Drama to Persuade.” Journal of Consumer Research 16 (3): 335-343.

Derbaix, Christian M. 1995. "The Impact of Affective Reactions on Attitudes Toward the Advertisement and the Brand: A Step Toward Ecological Validity.” Journal of Marketing Research: 470-479.

van Dijck, José. 2009. “Users Like You? Theorizing Agency in User-generated Content.” Media, Culture, and Society 31 (1): 41-58.

Van Doorn, Jenny, Katherine N. Lemon, Vikas Mittal, Stephan Nass, Doreen Pick, Peter Pirner, and Peter Verhoef. 2010. "Customer Engagement Behavior: Theoretical Foundations and Research Directions.” Journal of Service Research 13 (3): 247-252.

Eagly, Alice H., Wendy Wood, and Shelly Chaiken. 1978. "Causal Inferences About Communicators and Their Effect on Opinion Change.” Journal of Personality and Social Psychology 36 (4): 424-435.

Elliott, Stuart. 2010. “Do-it-yourself Super Ads.” The New York Times, February 8, New York edition.

Ertimur, Burçak, and Mary C. Gilly. 2011. "So Whaddya Think? Consumers Create Ads and Other Consumers Critique Them.” Journal of Interactive Marketing 26 (3): 115-130.

Evans, Liana. 2012. The Art of Consumer Engagement: Turning Consumers into Brand Evangelists. Upper Saddle River, NJ: Pearson Education.

Haven, Brian. 2007. “Marketing’s New Key Metric: Engagement”. Forrester Research.

Hilmert, Clayton J., James A. Kulik, and Nicholas J.S. Christenfeld. 2006. "Positive and Negative Opinion Modeling: The Influence of Another's Similarity and Dissimilarity.” Journal of Personality and Social Psychology 90 (3): 440.

Hollebeek, Linda. 2011. "Exploring Customer Brand Engagement: Definition and Themes.” Journal of Strategic Marketing 19 (7): 555-573.

Horovitz, Bruce. 2009. “'Two Nobodies from Nowhere’ Craft Winning Super Bowl Ad.” USA Today, December 31 edition. http://www.usatoday.com/money/advertising/admeter/2009admeter.htm.

Hovland, Carl I., and Walter Weiss. 1951. "The Influence of Source Credibility on Communication Effectiveness.” Public Opinion Quarterly 15 (4): 635-650.

Hoyer, Wayen D., Rajesh Chandy, Matilda Dorotic, Manfred Krafft, and Siddharth S. Singh. 2010. “Consumer Cocreation in New Product Development.” Journal of Service Research 13 (3): 283-296.

Ives, Nat. 2004. "Unauthorized Campaigns Used by Unauthorized Creators to Show Their Creativity Become a Trend.” The New York Times, December 23.

Kalehoff, Max. 2006. "Engagement Video Series: Dr. Joseph Plummer of the ARF." Engagement By Engagement. 
http://consumerengagement.blogspot.com/2006/09/engagement-video-series-drjoseph.html.

Keelan, Jennifer, Vera Pavri-Garcia, George Tomlinson, and Kumanan Wilson. 2007. "YouTube as a Source of Information on Immunization: a Content Analysis.” JAMA: The Journal of the American Medical Association 298 (21): 2482-2484.

Krugman, H.E. 1965. "The Impact of Television Advertising: Learning Without Involvement.” Public Opinion Quarterly 29 (3): 349-356.

Kumar, V., Lerzan Aksoy, Bas Donkers, Raj Kumar Venkatesan, Thorsten Wiesel, and Scott B. Tillmanns. 2010. "Undervalued or Overvalued Customers: Capturing Total Customer Engagement Value.” Journal of Service Research 13 (3): 297-310.

Lippert, Barbara. 2010. “Chips Off the Old Block.” Adweek.

MacKenzie, Scott B., Richard J. Lutz, and George E. Belch. 1986. "The Role of Attitude Toward the Ad as a Mediator of Advertising Effectiveness: A Test of Competing Explanations.” Journal of Marketing Research: 130-143.

Markeing NPVJournal. 2008. "How Do You Measure Engagement? Start by Defining It in the Right Context.” MarketingNPV Journal 5: 3-7.

Mayer, Roger C., James H. Davis, and F. David Schoorman. 1995. "An Integrative Model of Organizational Trust.” Academy of Management Review: 709-734.

McCroskey, James C., Virginia P. Richmond, and John A. Daly. 1975. “The Development of a Measure of Perceived Homophily in Interpersonal Communication.” Human Communication Research 1 (4): 323-332.

McPherson, Miller, Lynn Smith-Lovin, and James M. Cook. 2001. "Birds of a Feather: Homophily in Social Networks.” Annual Review of Sociology 27: 415-444.

Micu, Carmelia C., Robin A. Coulter, and Linda L. Price. 2009. "How Product Trial Alters the Effects of Model Attractiveness.” Journal of Advertising 38 (2): 69-82.

Mills, Elinor. 2006. "Advertisers Look to Grassroots Marketing.” CNET News.

Mollen, Anne, and Hugh Wilson. 2009. "Engagement, Telepresence and Interactivity in Online Consumer Experience: Reconciling Scholastic and Managerial Perspectives.” Journal of Business Research 63 (9-10): 919-25.

Moreau, C. Page, and Darren W. Dahl. 2005. "Designing the Solution: The Impact of Constraints on Consumers' Creativity.” Journal of Consumer Research 32 (1): 13-22.

Moscowitz, Robert. 2006. Imedia. Are Consumer Generated Ads Here to Stay. http://www.imediaconnection.com/content/9521.asp.

Muñiz, Albert M. Jr., and Hope J. Schau. 2007. "Vigilante Marketing and Consumer-created Communications.” Journal of Advertising 36 (3): 35-50.

Neisser, Drew. 2006. "Drew Neisser on Chevy Tahoe Advertising - CNBC the Closing Bell.” http://www.youtube.com/watch?v=1nMRs24Q4oQ.

O’Brien, H.L., and E.G. Toms. 2010. "The Development and Evaluation of a Survey to Measure User Engagement.” Journal of the American Society for Information Science and Technology 61 (1): 50-69.

Olson, Erik L., and Hans M. Thjømøe. 2011. "Explaining and Articulating the Fit Construct in Sponsorship." Journal of Advertising 40 (1): 57-70.

Paharia, Neeru, Anat Keinan, Jill Avery, and Juliet B. Schor. 2011. "The Underdog Effect: The Marketing of Disadvantage and Determination Through Brand Biography.” Journal of Consumer Research 37 (3): 775-790. 
Park, C.W., B.J. Jaworski, and D.J. Maclnnis. 1986. "Strategic Brand Concept-image Management.” The Journal of Marketing: 135-145.

Patton, Michael Q. 2001. Qualitative Research \& Evaluation Methods. Sage Publications.

Petrecca, Laura. 2012. “Doritos Ad Meter Winners Each Receive a \$1 Million Bonus.” USA Today, Feburary 9th edition.

Plummer, Joseph, ed. 2006. “Engagement: Definitions and Anatomy”. ARF - Advertising Research Foundation.

—. 2007. "Measures of Engagement”. ARF - Advertising Research Foundation.

Shimp, Terence A. 1981. "Attitude Toward the Ad as a Mediator of Consumer Brand Choice.” Journal of Advertising 10 (2): 9-48.

Singh, Tanuja, Michael H. Slotkin, and Alexander R. Vamosi. 2007. “Attitude Towards Ecotourism and Environmental Advocacy: Profiling the Dimensions of Sustainability.” Journal of Vacation Marketing 13 (2): 119-134.

Sirdeshmukh, Deepak, Jagdip Singh, and Barry Sabol. 2002. “Consumer Trust, Value, and Loyalty in Relational Exchanges.” Journal of Marketing 66 (1): 15-37.

Steyn, Peter, Michael T. Ewing, Gené van Heerden, Leyland F. Pitt, and Lydia Windisch. 2011. "From Whence It Came: Understanding Source Effects in Consumer Generated Advertising.” International Journal of Advertising 30 (1): 133-160.

Steyn, Peter, Åsa Wallström, and Leyland Pitt. 2010. “Consumer-generated Content and Source Effects in Financial Services Advertising: An Experimental Study.” Journal of Financial Services Marketing 15 (1): 49-61.

Thomaselli, Rich. 2010. "If Consumer Is Your Agency, It’s Time for a Review.” Advertising Age, May 17.

Thompson, Debora V., and Prashant Malaviya. 2011. "Consumer Response to User-generated Advertising: The Effects of Disclosing Consumers as Ad Creators.” Marketing Science Institute Working Paper Series (11-106).

Verhoef, Peter, Werner J. Reinartz, and Manfred Krafft. 2010. "Customer Engagement as a New Perspective in Customer Management.” Journal of Service Research 13 (3): 247-252.

Verlegh, Peeter W. J., Céline Verkerk, Mirjam A. Tuk, and Ale Smidts Smidts. 2004. "Customers or Sellers? The Role of Persuasion Knowledge in Customer Referral." Advances in Consumer Research 31 (1): 304-305.

Wiener, Joshua L., Raymond W. LaForge, and Jerry R. Goolsby. 1990. "Personal Communication in Marketing: An Examination of Self-interest Contingency Relationships.” Journal of Marketing Research 27 (2) (May 1): 227-231.

Wilson, Elizabeth J., and Daniel L. Sherrell. 1993. "Source Effects in Communication and Persuasion Research: a Meta-analysis of Effect Size.” Journal of the Academy of Marketing Science 21 (2): 101-112.

Wong, Elaine. 2009. "Why Frito-Lay Is Returning to Its Super Bowl Playbook.” Advertising Age, September 13.

Wright, Peter. 1986. "Schemer Schema: Consumers’ Intuitive Theories About Marketers' Influence Tactics.” Advances in Consumer Research 13 (1): 1-3.

Yalch, Richard F., and Rebecca Elmore-Yalch. 1984. "The Effect of Numbers on the Route to Persuasion.” Journal of Consumer Research 11 (1): 522-527.

Zaichkowsky, Judith Lynne. 1985. “Measuring the Involvement Construct.” Journal of Consumer Research 12 (3): 341-352. 